\title{
The prevalence of the methicillin resistant staphylococcus Aureus in the postoperative wound infection in a South Indian hospital
}

\author{
Jnaneshwara K.B ${ }^{1}$, Eshwar R.S ${ }^{2}$, Lava $\mathbf{R}^{3}$ \\ ${ }^{1}$ K. B Jnaneshwara, ${ }^{2}$ R. S Eshwar, ${ }^{3}$ R Lava, all authors are affiliated with Department of Microbiology, J.J.M. Medical \\ College, Davangere, Karnataka, India.
}

Address for Correspondence: R. Eshwar Singh, Associate Professor, Department of Microbiology, Gadag Institute of Medical Sciences, Gadag, Karnataka, India.

\section{Prevalence of MRSA}

\begin{abstract}
Introduction: Objectives of the present study was to find the prevalence of methicillin resistant staphylococcus aureus at a South Indian hospital. Methods: Hundred clinically suspected cases of infected postoperative wounds were subjected to culture and sensitivity. All the S.aureus isolates were screened for MRSA. Results: Prevalence of MRSA was $62.5 \%$. All the MRSA strains showed multidrug resistance except to Vancomycin and Cloxacillin. Conclusion: Judicious use of antibiotics, strict asepsis and proper hygiene should be strictly applied to reduce postoperative wound infections. The determination of prevalence and antimicrobial profile of MRSA will help the clinician while treating.
\end{abstract}

Keywords: MRSA; S.aureus; E.coli; Pseudomonas spp; Antimicrobial susceptibility; Multidrug resistance.

\section{Introduction}

Staphylococcus aureus has been reported as a major cause of community and hospital acquired infections [13]. The organism has a differential ability to spread and cause outbreaks in hospitals [4]. Ever since its first isolation in 1961, Methicillin resistant Staphylococcus aureus (MRSA) has emerged as one of the commonest causes of hospital acquired infection (HAI) and continues to remain an important factor contributing to failure of management. Most of the isolates of MRSA have acquired resistance to commonly available antibiotics in the market. Several reports have appeared in medical literature regarding the prevalence and incidence in hospitals across the globe including India. Infections due to MRSA are associated with increased

Manuscript received: $24^{\text {th }}$ May 2016

Reviewed: $5^{\text {th }}$ June 2016

Author Corrected: $16^{\text {th }}$ June 2016

Accepted for Publication: $30^{\text {th }}$ June 2016 morbidity and mortality in hospitalized patients. It also has the potential to cause sudden outbreaks in hospitals. Cost of treatment is another major problem faced by patients in the developing countries [5].

Despite the advances made in asepsis, antimicrobial drugs, sterilization and operation techniques, postoperative wound infections continues to be a major problem in all the branches of surgery in the hospitals and are responsible for the increasing cost, morbidity and mortality related to surgical operations.

Recent increase of methicillin resistant and multiple drug resistant strains at large hospitals has started to pose great difficulty in selecting antimicrobial agents [6]. Isolation of the organism and antimicrobial profile helps in the prompt management of postoperative 


\section{Research Article}

wound infection. Microbiology plays very important role in diagnosis of infection and guiding the physician regarding accurate antimicrobial therapy. Hence, this study was undertaken to isolate and determine the antibiotic susceptibility pattern of MRSA.

\section{Materials and Methods}

The present study was performed at the microbiology department of our institution. The present study included a total of 100 cases of postoperative wound infection. Among them 54 were from men and 46 were from women. The age group of the patients ranged between 3- 84 years. Most of the patients were in the age group of 16 through 30 years (45\%), 25\% was 31 through 45 years and 46-60 years (16\%) in that order. The cases were from the teaching hospital of our institution which is located in South India.

The wound infections other than the postoperative cases and the cases involving endoscopic procedures, incision and drainage of abscess, urethral dilations, slough excision and split skin graft were excluded from the present study. The patient should have a sutured wound in order to be considered in the present investigation.

The samples were collected from the depth of the wound with strict aseptic precautions with the help of dry sterile cotton swab sticks for bacteriological examination [6]. Two culture swabs from the each sample were obtained, one for the direct smear study and the other for aerobic culture which was immediately sent to the laboratory for investigation.

On day 1 , direct microscopic examination was done by gram stain to look for pus cells and the bacteria. The first swab was used for making smear by rolling the swab stick on a clean glass slide, which was heat fixed. Gram stained smear was examined under the microscope and the bacteria were segregated intococci and bacilli, grampositive orgram negative.

This report was then correlated with the growth in the culture plates after 18-24 hours. The second swab was inoculated on sheep blood agar and MacConkey agar as well as nutrient broth and incubated at $37^{\circ} \mathrm{C}$ for $18-24$ hours under the aerobic conditions. The culture media were procured from Hi- Media laboratory and prepared as per manufacturer's recommendation as well as inputs from Mackie and McCartney [7].

On day 2, identification of the growth was performed and the morphology of the colonies on the blood agar and McConkey agar were studied. Smear from the colonies were prepared and stained with gram stain and segregated into gram positive and negative after the microscopic examination. The bacteria were further microbiologically segregated by using the relevant biochemical and physiological tests $[8,9]$.

The antibiotic susceptibility was studied by using the Kirby-Bauer disc diffusion method. Three to five isolated colonies of similar morphology were inoculated and the incubation was done for 2-8 hours, until the turbidity of the broth is matched. The antibiotic discs were placed on the agar plate within 15 minutes of inoculation by using a sterile needle and pressed firmly against the plate. The plates were inverted and incubated for $18-24$ hours at $37^{\circ} \mathrm{C}$.

On the day 3, the final identification of the bacteria was made taking into account of the various biochemical and physiological tests. Antibiotic susceptibility pattern were reported by measuring the zone of inhibition with a millimeter scale.

The antibiotic disc was reported as susceptible, intermediate and resistant, based on the criteria provided by NCCLS [10]. The catalase test was done to differentiate Staphylococcus (catalase positive) from Streptococcus and Enterococcus (both are catalase negative).

Enterococcus was identified presumptively by inoculating into $6.5 \% \mathrm{NaCl}$ broth (salt tolerance) and observing the turbidity. If there was no turbidity, it was considered as Streptococcus. Enterococcus was further identified by heat tolerance (which is surviving at $60^{\circ} \mathrm{C}$ for 30 minutes). The identification of the gram negative bacilli was also performed. Oxidase positive isolates, 
which were suspected to be Pseudomonas spp, were further identified by positive Citrate utilization test. Oxidase negative isolates were presumptively identified as Acinetobacter and Enterobacteriaceae members. Acinetobacter was identified following an oxidative reaction or inert reaction when inoculated into $\mathrm{O} / \mathrm{F}$ medium (Oxidative/ Fermentative medium). The Enterobacteriaceae was differentiated by lactose into lactose fermenters and non-lactosefermenters.Lactose fermenters were subjected to motility and IMViC test and production of $\mathrm{H}_{2} \mathrm{~S}$ was observed on T.S.I agar. The non-lactose fermenters were inoculated into urease medium. Proteus spp were presumptively identified by Urea hydrolysis and further confirmed by Phenyl alanine deaminase positive test.

\section{Results}

In the 100 cases of the present study, about 111 bacteria were observed accounting for 1.1 bacteria per case as an average. All these 111 isolates were aerobes and facultative anaerobes. The grams stain of all direct smears correlated well with the growth on culture. Of these 111 isolates, $36(32.4 \%)$ were gram positive cocci and $75(67.6 \%)$ were gram negative bacilli. E. coli was isolated most frequently (24.3\%) followed by S. aureus (21.6\%), Pseudomonas spp (20.7\%), Klebsiellaspp (13.5\%) and Coagulase negative Staphylococci (7.2\%).

The patterns of bacteria isolated in the present study group are represented in Figure 1. Out of the 100 clinical samples, 85 samples (85\%) yielded growth of single bacterium (monomicrobial/pure growth), 13 samples (13\%) yielded growth of more than one bacterium (polymicrobial/mixture) and 2 samples (2\%) yielded no growth. Staphylococcus Aureus was the most common bacteria $(91.7 \%)$ isolated in pure culture, which is followed by Pseudomonas sp $(82.6 \%)$.

In mixed growth the common bacteria isolated were E. coli (33.3\%) and Klebsiellaspp (33.3\%). Coagulase negative Staphylococci (100\%) and Acinetobacter (100\%) were isolated exclusively in pure culture.

Enterococcus spp and Proteus spp were isolated equally in both pure growth and mixtures, while Citrobacterspp and Enterobacterspp both were isolated only in mixed cultures (50\% each). The bacterial isolates in pure growth and mixtures in post-operative wound infection of the present study are represented in Table 1.

Table-1: Showing the distribution of the bacterial isolates $(n=111)$ in pure growth and mixtures in postoperative wound infection.

\begin{tabular}{|c|c|c|}
\hline Bacteria $(\mathbf{n = 1 1 1})$ & Pure (n1=85) & Mixture (n2=26) \\
\hline E. coli $(\mathrm{n}=27)$ & $18(66.7 \%)$ & $2(8.3 \%)$ \\
\hline S. aureus $(\mathrm{n}=24)$ & $22(91.7 \%)$ & $4(17.4 \%)$ \\
\hline Pseudomonas spp $(\mathrm{n}=23)$ & $19(82.6 \%)$ & $5(33.3 \%)$ \\
\hline Klebsiellaspp $(\mathrm{n}=15)$ & $10(66.7 \%)$ & Nil \\
\hline$*$ CONS $(\mathrm{n}=8)$ & $8(100 \%)$ & Nil \\
\hline Enterococcus spp $(\mathrm{n}=4)$ & $2(50 \%)$ & $1(100 \%)$ \\
\hline Acinetobacterspp $(\mathrm{n}=4)$ & $4(100 \%)$ & $1(100 \%)$ \\
\hline Proteus spp $(\mathrm{n}=4)$ & $2(50 \%)$ & Nil \\
\hline Citrobacterspp $(\mathrm{n}=1)$ & Nil & \\
\hline Enterobacterspp $(\mathrm{n}=1)$ & & $2(50 \%)$ \\
\hline
\end{tabular}

*CONS-Coagulase negative Staphylococci 


\section{Research Article}

Out of the 100 clinical samples taken, 49 were from the abdomen, 45 were from limbs, 5 were from groin and 1 was from the neck region.

The frequency of bacteria of postoperative wound infection in relation to site of operation is represented in Table 2. Out of 111 isolates obtained from postoperative wound infection, 58 isolates were found to be from the abdominal surgery (52.2\%) followed by 47 isolates from limb surgery $(42.3 \%)$. S. aureus was resistant to penicillin in $95.8 \%$ isolates, ciprofloxacin $(91.7 \%)$, cephalexin $(79.2 \%)$ and erythromycin $(79.2 \%)$.

Susceptibility of S. aureus was $100 \%$ to Vancomycin followed by Cloxacillin (79.2\%) and Amikacin (50\%). Among Enterococcus spp, resistance to Penicillin was $100 \%$ followed by Cloxacillin (75\%). All of them exhibited the susceptibility to Vancomycin.

The susceptibility pattern of gram positive cocci has been represented in Table 3. Susceptibility of E. coli was more to Amikacin (63\%) and Chloramphenicol (59.3\%), but resistance was highest to Ampicillin (96.3\%) followed by Cotrimoxazole (85.2\%), Sparfloxacin (81.5\%), Ciprofloxacin (77.8\%), Gentamicin (77.8\%), Cephotaxime (77.8\%) and Ceftazidime $(74.1 \%)$.

Klebsiellaspp showed greater resistance to almost all the antibiotics. The resistance was $100 \%$ to Ampicillin followed by Cotrimoxazole (93.3\%), Gentamicin (86.7\%), Sparfloxacin (86.7\%), Ciprofloxacin (80\%), Cephotaxime (73.3\%), Ceftazidime (73.3\%), Chloramphenicol (66.7\%) and Amikacin (66.7\%).

The susceptibility patterns of gram negative bacilli are given in table nos. $4 \& 5$. The Pseudomonas spp showed maximum susceptibility to Polymyxin B (87\%) followed by Amikacin (56.5\%), Ceftazidime (52.2\%), Piperacilin (52.2\%) and Carbenicillin (39.1\%). The susceptibility pattern of Pseudomonas spp. is given in table no 6.

Table-2: bacteriology of the postoperative wound infection in relation to site of operation.

\begin{tabular}{|c|c|c|c|c|}
\hline Bacteria & $\begin{array}{c}\text { Abdomen } \\
(\mathrm{n}=\mathbf{5 8}, \mathbf{5 2 . 2 5 \%})\end{array}$ & $\begin{array}{c}\text { Limbs } \\
(\mathrm{n}=47,42.34 \%)\end{array}$ & $\begin{array}{c}\text { Groin } \\
(\mathrm{n}=5, \mathbf{4 . 5 \%})\end{array}$ & $\begin{array}{c}\text { Neck } \\
(\mathrm{n}=1,0.9 \%)\end{array}$ \\
\hline E. coli $(n=27)$ & 22 & 3 & 2 & - \\
\hline S. aureus $(n=24)$ & 9 & 13 & 2 & - \\
\hline Pseudomonas sp $(n=23)$ & 11 & 11 & - & 1 \\
\hline Klebsiellasp $(\mathrm{n}=15)$ & 5 & 10 & - & - \\
\hline Coagulase negative Staphylococci $(n=8)$ & 3 & 4 & 1 & - \\
\hline Enterococcus sp $(n=4)$ & 2 & 2 & - & - \\
\hline Acinetobactersp $(n=4)$ & 2 & 2 & - & - \\
\hline Proteus spp $(n=4)$ & 2 & 2 & - & - \\
\hline Citrobactersp $(\mathrm{n}=1)$ & 1 & - & - & - \\
\hline Enterobactersp $(\mathrm{n}=1)$ & 1 & - & - & - \\
\hline
\end{tabular}


Research Article

Table-3: Susceptibility pattern of gram positive cocci in postoperative wound infection.

\begin{tabular}{|c|c|c|c|c|c|c|}
\hline & $\begin{array}{c}\text { S. Aureus } \\
(\mathbf{n}=\mathbf{2 4})\end{array}$ & & & & \multicolumn{2}{|c|}{ Enterococcus spp. (n=4) } \\
\hline Susceptibility & $\mathrm{S}$ & $\mathrm{R}$ & $\mathrm{S}$ & $\mathrm{R}$ & \multicolumn{2}{|c|}{$\mathrm{S}$} \\
\hline penicillin & $1(4.3 \%)$ & $23(95.7 \%)$ & $2(25 \%)$ & $6(75 \%)$ & $0(0 \%)$ & $4(100 \%)$ \\
\hline cloxacillin & $19(79.2 \%)$ & $5(20.8 \%)$ & $4(50 \%)$ & $4(50 \%)$ & $3(75 \%)$ & $1(25 \%)$ \\
\hline erythromycin & $5(20.8 \%)$ & $19(79.2 \%)$ & $3(37.5 \%)$ & $5(62.5 \%)$ & $2(50 \%)$ & $2(50 \%)$ \\
\hline cephalexin & $5(20.8 \%)$ & $19(79.2 \%)$ & $1(12.5 \%)$ & $7(87.5 \%)$ & $2(50 \%)$ & $2(50 \%)$ \\
\hline amikacin & $12(50 \%)$ & $12(50 \%)$ & $5(62.5 \%)$ & $3(37.5 \%)$ & $2(50 \%)$ & $2(50 \%)$ \\
\hline gentamicin & $7(29.2 \%)$ & $17(70.8 \%)$ & $2(25 \%)$ & $6(75 \%)$ & $1(25 \%)$ & $3(75 \%)$ \\
\hline ciprofloxacin & $2(8.3 \%)$ & $22(91.7 \%)$ & $2(25 \%)$ & $6(75 \%)$ & $2(50 \%)$ & $2(50 \%)$ \\
\hline cotrimoxazole & $7(29.2 \%)$ & $17(70.8 \%)$ & $0(0 \%)$ & $8(100 \%)$ & $2(50 \%)$ & $2(50 \%)$ \\
\hline vancomycin & $24(100 \%)$ & $0(0 \%)$ & $8(100 \%)$ & $0(0 \%)$ & $4(100 \%)$ & $0(0 \%)$ \\
\hline
\end{tabular}

*CONS-Coagulase negative Staphylococci; S-Susceptible; R-Resistant

Table-4: Susceptibility patterns of gram negativebacilli (E. coli, Klebsiella sp. and Proteus sp.) in postoperative wound infection.

\begin{tabular}{|c|c|c|c|c|c|c|}
\hline & E. coli (n=27) & & \multicolumn{2}{|c|}{ Klebsiella spp. (n=15) } & \multicolumn{2}{|c|}{ Proteus spp. (n=4) } \\
\hline Susceptibility & $\mathrm{S}$ & $\mathrm{R}$ & $\mathrm{S}$ & $\mathrm{R}$ & $\mathrm{S}$ & $\mathrm{R}$ \\
\hline Ampicillin & $1(3.7 \%)$ & $26(96.3 \%)$ & $0(0 \%)$ & $15(100 \%)$ & $0(0 \%)$ & $4(100 \%)$ \\
\hline Cefotaxime & $6(22.2 \%)$ & $21(77.8 \%)$ & $4(26.7 \%)$ & $11(73.3 \%)$ & $0(0 \%)$ & $4(100 \%)$ \\
\hline Ceftazidime & $7(25.9 \%)$ & $20(74.1 \%)$ & $4(26.7 \%)$ & $11(73.3 \%)$ & $2(50 \%)$ & $2(50 \%)$ \\
\hline Amikacin & $17(63 \%)$ & $10(37 \%)$ & $5(33.3 \%)$ & $10(66.7 \%)$ & $2(50 \%)$ & $2(50 \%)$ \\
\hline Gentamicin & $6(22.2 \%)$ & $21(77.8 \%)$ & $2(13.3 \%)$ & $13(86.7 \%)$ & $1(25 \%)$ & $3(75 \%)$ \\
\hline Ciprofloxacin & $6(22.2 \%)$ & $21(77.8 \%)$ & $3(20 \%)$ & $12(80 \%)$ & $1(25 \%)$ & $3(75 \%)$ \\
\hline Sparfloxacin & $5(18.5 \%)$ & $22(81.5 \%)$ & $2(13.3 \%)$ & $13(86.7 \%)$ & $1(25 \%)$ & $3(75 \%)$ \\
\hline Cotrimoxazole & $4(14.8 \%)$ & $23(85.2 \%)$ & $1(6.7 \%)$ & $14(93.3 \%)$ & $0(0 \%)$ & $4(100 \%)$ \\
\hline Chloramphenicol & $16(59.3 \%)$ & $11(40.7 \%)$ & $5(33.3 \%)$ & $10(66.7 \%)$ & $1(25 \%)$ & $3(75 \%)$ \\
\hline
\end{tabular}

S-Susceptible; R-Resistant 


\section{Research Article}

Table-5: Susceptibility patterns of Acinetobacter sp., Citrobacter sp. and Enterobacter sp.(gram negativebacilli) in postoperative wound infection.

\begin{tabular}{|c|c|c|c|c|c|c|}
\hline & \multicolumn{2}{|c|}{ Acinetobacter sp. (n=4) } & \multicolumn{2}{c|}{ Citrobacter sp. (n=1) } & \multicolumn{2}{c|}{ Enterobacter sp. (n=1) } \\
\hline Susceptibility & $\mathrm{S}$ & $\mathrm{R}$ & $\mathrm{S}$ & $\mathrm{R}$ & $\mathrm{S}$ & $\mathrm{R}$ \\
\hline Ampicillin & $0(0 \%)$ & $4(100 \%)$ & $0(0 \%)$ & $1(100 \%)$ & $1(100 \%)$ & $0(0 \%)$ \\
\hline Cefotaxime & $2(50 \%)$ & $2(50 \%)$ & $0(0 \%)$ & $1(100 \%)$ & $0(0 \%)$ & $1(100 \%)$ \\
\hline Ceftazidime & $2(50 \%)$ & $2(50 \%)$ & $1(100 \%)$ & $0(0 \%)$ & $1(100 \%)$ & $0(0 \%)$ \\
\hline Amikacin & $3(75 \%)$ & $1(25 \%)$ & $0(0 \%)$ & $1(100 \%)$ & $1(100 \%)$ & $0(0 \%)$ \\
\hline Gentamicin & $2(50 \%)$ & $2(50 \%)$ & $0(0 \%)$ & $1(100 \%)$ & $0(0 \%)$ & $1(100 \%)$ \\
\hline Ciprofloxacin & $1(25 \%)$ & $3(75 \%)$ & $1(100 \%)$ & $0(0 \%)$ & $0(0 \%)$ & $1(100 \%)$ \\
\hline Sparfloxacin & $1(25 \%)$ & $3(75 \%)$ & $0(0 \%)$ & $1(100 \%)$ & $0(0 \%)$ & $1(100 \%)$ \\
\hline Cotrimoxazole & $1(25 \%)$ & $3(75 \%)$ & $0(0 \%)$ & $1(100 \%)$ & $0(0 \%)$ & $1(100 \%)$ \\
\hline Chloramphenicol & $3(75 \%)$ & $1(25 \%)$ & $1(100 \%)$ & $0(0 \%)$ & $0(0 \%)$ & $1(100 \%)$ \\
\hline
\end{tabular}

S-Susceptible; R-Resistant

Table- 6: Susceptibility pattern of Pseudomonas spp. in postoperative wound infection.

\begin{tabular}{|c|c|c|}
\hline & \multicolumn{2}{|c|}{ Pseudomonas spp. (n=23) } \\
\hline Susceptibility & $\mathrm{S}$ & $\mathrm{R}$ \\
\hline Cefotaxime & $3(13 \%)$ & $11(47.8 \%)$ \\
\hline Ceftazidime & $12(52.2 \%)$ & $10(43.5 \%)$ \\
\hline Amikacin & $13(56.5 \%)$ & $15(65.2 \%)$ \\
\hline Gentamicin & $8(34.8 \%)$ & $21(91.3 \%)$ \\
\hline Ciprofloxacin & $2(8.7 \%)$ & $3(13 \%)$ \\
\hline Sparfloxacin & $20(87 \%)$ & $14(60.9 \%)$ \\
\hline polymyxin B & $9(39.1 \%)$ & $11(47.8 \%)$ \\
\hline Carbenicillin & $12(52.2 \%)$ & 20 \\
\hline
\end{tabular}

S-Susceptible; R-Resistant

\section{Discussion}

There are several predisposing causesto the emergence of postoperative infected wounds. The patient characteristics which favor the postoperative wound infections include coincident remote site infections or colonization, use of systemic steroids, diabetes mellitus, and history of cigarette smoking, obesity and old age. The poor nutrition, transfusion of certain blood products before and after the surgery, preoperative hospitalizationcan also add into it. The environmental factors can prevent phagocytic cells from functioning 
efficiently by lowering tissue oxygen tension $\left(\mathrm{PO}_{2}\right)$. The lowered $\mathrm{PO}_{2}$ inhibits the phagocytosis and will enhance the growth of anaerobic microorganisms [11]. For the most nosocomial wound infections, the endogenous flora of the patient which is present in the body surface and the visceramay become the source of infection [12]. The operating surgeon can decrease the chances of postoperative wound infectionby using the drains appropriately, avoiding excessive cautery and not performing intestinal anastomoses if there is any possibility of ischemia.

Perhaps Streptococcus pyogens wasthe most important cause of the hospital acquired infectionsearlier is now hardly ever encountered as it is highly susceptible to the antibiotics. Tetanus spores can survive in the dust for a very long time. Hospital acquired tetanus is usually a result of faulty sterilization techniques or other lapses in asepsis [13]. It has been reported that the balance between the host immunity and bacterial virulence has been altereddue to the use of higher antibacterial agents [14].

In the present study, the gram negative bacillary infections $(67.6 \%)$ had a high prevalence than those due to gram positive $(32.4 \%)$ in the postoperative wound infections. This predominance of gram negative bacteria in the postoperative wound infection in the present investigation is in conformity with the findings of Agarwal et al. [15] and Anvikar et al. [3] E. coli was the commonly isolated strain in the present investigation, accounting for $24.3 \%$ of all the isolates.

The present surgery observed that 22 out of 27 isolates of E.coli were from the postoperative wound infection following an abdominal surgery. S. Aureus was the next accounting for $21.6 \%$ of all the isolates. Among them 24 isolates of S. Aureus were isolated from the limb surgery. Agarwal et al. [15] described the predominance of E.coli (31.31\%) followed by the S. Aureus (29.29\%) in the postoperative wound infections. The pseudomonas species was accounting for $20.7 \%$ of all the isolates. This is similar to Anvikar et al.,[3] in their study the isolation of pseudomonas spp. was $25 \%$. But the isolation of Klebsiella spp. in the present study
(13.5\%) is lesser compared to Anvikaret al. [3] which showed Klebsiella spp. $(28.8 \%)$ as the emerging hospital acquired pathogen. Amikacin, cloxacillin and vancomycin were the most effective antimicrobial agents against the gram positive cocci, in the present investigation. The higher susceptibility of S.aureus to the cloxacillinwas $79.2 \%$ in the present study, which is similar to that of Kowli et al., [16] where it was $76 \%$.

The rapid emergence of S.aureus resistant to variety of antibiotics is of a great concern. The resistance to Penicillin is $95.8 \%$ followed by Ciprofloxacin (91.7\%), Cephalexin (79.2\%), Erythromycin (79.2\%) and Gentamicin (70.8\%). This may be due to the increasing use of betalactam antibiotics and Gentamicin. Lack of antibiotic policy is one more probable contributing factor.

Amikacin showed maximum efficacy against E.coli (63\%) followed by Chloramphenicol (59.3\%), while resistance to $3 \mathrm{rd}$ generation cephalosporin ranged from $74.1 \%$ to $77.8 \%$. The values of the present study are similar with the observations of Arya M et al. [17]. These findings of the present study are similar to that of Anvikar et al. [3] Against Pseudomonas spp., Polymyxin B showed maximum sensitivity of $87 \%$ followed by Amikacin (56.5\%). These data are lesser compared to that of Kumar AP et al. [18] in which sensitivity to Polymyxin B was $100 \%$. The present study observed the less effectiveness of the Fluoroquinolones.

The resistance to Sparfloxacin and Ciprofloxacin were $91.3 \%$ and $65.2 \%$ respectively. Resistance to Cephotaxime was $87 \%$. These observations of resistance pattern to many antibiotics aresimilar to the findings of Arya $\mathrm{M}$ et al [17].

\section{Conclusion}

The postoperative wound infection is the commonest nosocomial infection only after the urinary tract infection. The present microbiological study has determined the bacteriology (aerobes and facultative anaerobes) of postoperative wound infection. The most 
common bacteria isolated in pure culture were $\mathrm{S}$. aureus followed by Pseudomonas spp. The majority of E.coli isolates were from infections following abdominal surgery. The gram positive cocci showed uniform susceptibility to Vancomycin. Cloxacillin was the second best drug effective against gram positive cocci. S.aureus displayed maximum resistance against Penicillin, Ciprofloxacin and Erythromycin. E.coli showed maximum susceptibility to Amikacin and Chloramphenicol. Klebsiella spp. displayed maximum resistance to all the antibiotics, including Aminoglycosides, Fluoroquinolones and third generation Cephalosporins. Pseudomonas spp. exhibited maximum susceptibility to Polymyxin B and displayed maximum resistance to Sparfloxacin and Cephotaxime.

We suggest that it is necessary to implement urgent measures for restriction of nosocomial infections. Judicious use of antibiotics, strict asepsis and proper hygiene should be applied. We believe that the data of the present study may provide useful guidelines for choosing the effective therapy against the isolates from postoperative infected wound. It is advisable to scrutinize the postoperative infected wound in each and every hospital to evolve the control strategies.

Funding: Nil, Conflict of interest: None initiated,

Permission from IRB: Yes

\section{References}

1. Weinstein RA. Infection control in the hospital. In: Braunwald E, Fauci AS, Kasper DL, Hauser SL, Longo DL, Jameson JL, editors. Harrison's principles of internal medicine. 15th ed., New York: McGraw- Hill, 2001;1: 853-856.

2. Crook DWM, Bowler ICJ. Nosocomial infections. In: Weatherall DJ, Ledingham JGG, Warrell DA, editors. Oxford textbook of medicine. 3rd ed., Oxford: Oxford University Press, 1996:327-331.

3. Anvikar AR, Deshmukh AB, Karyakarte RP, Damle AS, Patwardhan NS, Malik AK, et al. A one year prospective study of 3280 surgical wounds. Indian J Med Microbiol 1999;17(3):129-132.
4. Ritter MA, French ML, Eitzen H. Evaluation of microbial contamination of surgical gloves during actual use. Clin Orthop RelatRes.1976 Jun;(117):303-6.

5. Cruse P. Wound infection surveillance. Rev Infect Dis. 1981 Jul-Aug;3(4):734-7.

6. Forbes BA, Sahm DF, WeissfeldAS. Bailey \& Scott's. Diagnostic microbiology. 11th ed., St. Louis: Mosby, 2002.

7. Collee JG, Marr W. Specimen collection, culture containers and media. In: Collee JG, Fraser AG, Marmion BP, Simmons A, editors. Mackie \& McCartney practical medical microbiology 14th ed., New York: Churchill Livingstone, 1996:95-111.

8. Collee JG, Miles RS, Watt B. Tests for the identification of bacteria. In : Collee JG, Fraser AG, Marmion BP, Simmons A, editors. Mackie and Mc Cartney practical medical microbiology, 14th ed., New York: Churchill Livingstone, 1996;131-149.

9. Cheesbrough M. District laboratory practice in tropical countries-part 2 Microbiology, Low Price ed., Cambridge: Cambridge University Press, 2000.

10. Ferraro MJ, Craig WA, Dubley MN, Eliopoulos G, Hecht DW, Hindler JF et al. Performance standards for antimicrobial susceptibility testing; Twelfth informational supplement. Pennsylvania: NCCLS, 2002;22(1):M100-S12.

11. Howard RJ. Surgical infections. In: Schwartz SI, Shires GT, Spencer FC, Husser WC, editors. Principles of surgery. 6th ed., New York: McGraw-Hill, 1994; 145-173.

12. Paul SM, Genese C, Spitalny K. Postoperative group A beta-hemolytic Streptococcus outbreak with the pathogen traced to a member of a healthcare worker's household. Infect Control Hosp Epidemiol. 1990 Dec;11(12):643-6. 


\section{Research Article}

13. Ananthanarayan R, Panikar CJK, editors. Textbook of microbiology, 5th ed., Chennai : Orient Longman, 2005.

14. Robson MC. Infection in the surgical patient: an imbalance in the normal equilibrium. Clin Plast Surg. 1979 Oct;6(4):493-503.

15. Agarwal PK, Agarwal M, Bal A, Gahlaut YVS. Incidence of post-operative wound infection at Aligarh. Indian J of Surg 1984;46(6\&7):326-333.
16. Kowli SS, Nayak MH, Mehta AP, Bhalerao RA. Hospital Infection. Indian J of Surg 1985;48:475-486.

17. Arya M, Arya PK, Biswas D, Prasad R. Antimicrobial susceptibility pattern of bacterial isolates from post-operative wound infections. Indian $\mathrm{J}$ Pathol Microbiol. 2005 Apr;48(2):266-9.

18. Kumar AP, Mithlesh A, Ashok B, Halim T. Epidemiology of Pseudomonas aeruginosa: postoperative wound sepsis. Indian J Pathol Microbiol. 1985 Apr;28(2):137-46.

\section{How to cite this article?}

Jnaneshwara K.B, Eshwar R.S, Lava R. The prevalence of the methicillin resistant staphylococcus Aureus in the postoperative wound infection in a South Indian hospital. Trop J Path Micro 2016;2(2):31-39. doi: 10.17511/jopm.2016.i02.01 